Insecure People in Insecure Places: The Influence of Regional Unemployment on Workers' Reactions to the Threat of Job Loss*

\author{
Paul Glavin Marisa Young** \\ McMaster University
}

Accepted for Publication at the Journal of Health and Social Behavior

* Direct all correspondence to Paul Glavin, Department of Sociology, McMaster University, 1280 Main St. W. Hamilton, Ontario Canada L8S 4M4. E-mail: glavinp@mcmaster.ca A grant award from the Canadian Institutes of Health Research (CIHR) supports this study (Funding Reference Number: MOP-102730; Scott Schieman, P.I).

** Both authors contributed equally to this manuscript.

Running Head: Insecure people in Insecure Places

Word count (including all text and references): 11,1116 


\section{Insecure People in Insecure Places: The Influence of Regional Unemployment on Workers' Reactions to the Threat of Job Loss}

\section{ABSTRACT}

Social comparison theory predicts that unemployment should be less distressing when the experience is widely shared, but does this prediction extend beyond the unemployed to those who are at risk of job loss? Research demonstrates a link between aggregate unemployment and employed individuals' perceptions of job insecurity; however, less is known about whether the stress associated with these perceptions is shaped by others' unemployment experiences. We analyze a nationally representative sample of Canadian workers (CAN-WSH study; N=3,900) linked to census data, and test whether regional unemployment influences the mental health consequences of job insecurity. Multilevel analyses provide more support for the social norm of insecurity hypothesis over the amplified threat hypothesis: the health penalties of job insecurity are weaker for individuals in high unemployment regions. This contingency is partially explained by the ability of insecure workers in poor labor market contexts to retain psychological resources important for protecting mental health. 


\section{Insecure People in Insecure Places: The Influence of Regional Unemployment on Workers' Reactions to the Threat of Job Loss}

\section{INTRODUCTION}

Epidemiologists and health scholars have long acknowledged the importance of context in the study of stress and mental health (Kawachi and Berkman 2003; O'Campo and Dunn 2012). This is particularly evident in research examining the relationship between labor market context and the health penalties of unemployment. Scholars have shown that these penalties are shaped not only by the unemployed's access to personal resources (e.g. financial and social support), but also by the extent that others around them are similarly affected by unemployment. When unemployment is more prevalent — such as during an economic recession - the unemployed tend to report fewer health consequences (Clark 2003; Flint et al. 2013; Powdthavee 2007). Some have interpreted this finding as evidence for the operation of a social comparison process (Festinger 1954), whereby the stress and stigma associated with unemployment is reduced when the experience is perceived as being common or universal (Clark 2003).

In this paper, we consider whether the influence of others' unemployment extends beyond the experiences of displaced workers to include those who are tenuously employed. While there is evidence that high unemployment levels are associated with increased perceptions of job insecurity among the employed, there is limited research on whether poor labor market conditions also influence the degree that these perceptions are distressing (Tausig and Fenwick 1999; see Clark, Knabe, and Rätzel 2010 for a European exception). We address this overlooked issue by analyzing a nationally representative sample of Canadian workers linked to census data to explore whether regional unemployment levels modify the association between perceived job insecurity and mental health.

We test two competing hypotheses about how labor market context might influence the 
stress of perceived job insecurity. Informed by social comparison theory, the social norm of insecurity hypothesis predicts that job insecurity should be perceived as more normative and therefore less distressing when aggregate unemployment is high (Clark et al. 2010; Festinger 1954). In contrast, the amplified threat hypothesis predicts that job insecurity should be most distressing in poor labor market contexts because of the limited opportunities for re-employment in the event of job loss (Lam, Fan, and Moen 2013). We test these hypotheses based on a nationally representative sample of Canadian workers $(\mathrm{N}=6,004)$ collected as part of the Canadian Work, Stress and Health study (CAN-WSH). We use an analytical sub-sample from these data of 3,900 employed respondents, connected to census division-level unemployment data ( $N=279$ census divisions). Linking these datasets enables us to examine how regional unemployment rates shape CAN-WSH respondents' experiences of job insecurity. In the following section, we review the existing literature on the links between aggregate economic conditions and individual health. We then discuss theoretical and empirical research that informs our investigation of how these conditions might shape personal reactions to job insecurity.

\section{LITERATURE REVIEW}

\section{Aggregate Unemployment and Mental Health}

Research generally finds that economic contractions compromise individuals' mental health (Brenner 1973; Fenwick and Tausig 1994; Hill and Maimon 2013). The most consistent association between economic decline and mental health has been observed using aggregate unemployment rates (Tausig and Fenwick 2012). Interpretations of these patterns suggest that higher rates of unemployment lead those who remain employed to downwardly reassess perceptions of their job security, producing feelings of anxiety and anger that erode mental health with prolonged exposure (Burgard et al. 2009; Glavin 2015; Lam et al. 2013). Economic 
contractions may also lead firms to restructure their operations in ways that place greater job pressures on surviving workers, thus exposing them to further stress (Quinlan and Bohle 2009)

Despite the general association between aggregate unemployment and mental health, there is compelling evidence that high unemployment levels may actually alleviate some of the stress experienced by the unemployed (Clark 2003; Flint et al. 2013; Jackson and Warr 1987; Powdthavee 2007). Others have shown that suicide ideation and follow through among the unemployed are more prevalent when overall unemployment rates are low (Platt and Kreitman, 1990; Platt, Micciolo, and Tansella 1992). Clark's (2003) research best documents these patterns using the 1991-1997 British Household Survey: his results suggest that the health penalties of unemployment were smaller among individuals residing in areas of Britain most affected by unemployment. Clark reports that these penalties decrease even further among those who lived with an unemployed partner.

Potential explanations for the weaker effects of unemployment within poor labor market contexts are two-fold. First, common experiences of unemployment among residents may spawn a generalized sense of collective social support from others in geographical propinquity by fostering and disseminating the belief that others endure similar experiences (Lin, Le, and Ensel 1999) — in this case, similar experiences of unemployment. Sharing similar experiences enhances the perception of empathetic understanding and emotional support (Pillemer and Suitor 1996; Suitor and Keeton 1997), and as Young and Wheaton (2013, p.484) argue: "the very notion of sharing a common stressor lowers its potential threat."

Second, common experiences of unemployment allow for social comparisons that may reduce its deleterious effects by offering a relative vantage point. These ideas resonate with social comparison theory (Festinger 1954), which argues that high unemployment rates may 
normalize and de-stigmatize negative self-appraisals by the unemployed (Clark 2003). Applied to the labor market, greater numbers of individuals actively seeking work serves to create what Clark (2003) refers to as a social norm of unemployment that the unemployed evaluate their personal circumstances against. When the experience is perceived as widely shared, the unemployed may be less likely to make personal attributions regarding the cause of their status loss, and engage in fewer negative self-evaluations (Festinger 1954).

\section{Job Insecurity and Mental Health in Context}

While the relationship between aggregate employment conditions and individual responses to job loss is relatively well established, there have been fewer efforts to examine how economic conditions shape experiences of particular segments of the employed labor forceespecially those in uncertain employment situations. This issue is worthy of investigation for several reasons. First, while unemployment and job loss have been consistently shown to have negative health consequences, they are less common compared to experiencing the threat of job loss (Kalleberg 2009). Evidenced in a national study of American workers surveyed in 2007, while seven percent of study participants reported a job loss in the twelve months prior to the interview, approximately twenty percent perceived their current job as insecure (Glavin 2015). These figures are corroborated by other studies of perceived job insecurity and unemployment, and have been interpreted as a consequence of the growth of precarious work arrangements in North America over the last four decades (Farber 2010; Fullerton and Wallace 2007).

Second, there is mounting evidence that job insecurity may have equal or potentially greater mental health consequences than actual job loss (Burgard et al. 2009). Job insecurity operates as a chronic stressor without a definitive start or end point; one of which creates anticipatory anxiety over the potential loss of economic and social resources that are linked to 
employment (Jahoda 1982; Sverke and Hellgren 2002; Wheaton 1999). Coupled with this anxiety is the uncertainty that insecure workers have over the timing of job loss. This uncertainty about the future can render coping strategies ineffective, adding to the distressing nature of the experience (Burgard et al. 2009; Lazarus and Folkman 1984). Numerous studies over the last two decades support these explanations, and have demonstrated a link between threatened employment and health for workers across a wide range of occupations and job sectors (Burgard et al. 2009; Ferrie et al. 1995; Fullerton and Anderson 2013).

Given the deleterious mental health consequences associated with perceived job insecurity, how might broader economic conditions influence the magnitude of these consequences? The limited research that has addressed this question has produced conflicting results. Lam and colleagues (2013) use the American General Social Survey to examine the association between perceptions of job insecurity and well-being in the aftermath of the Great Recession in 2010 and in a pre-recession period in 2006. The authors find a stronger association between job insecurity and reduced well-being during the recessionary aftermath in 2010 - but only among men.

Contrary to this finding, Clark and colleagues (2010) analyzed 23 waves of the German Socio Economic Panel study to examine whether regional variations in unemployment shaped the well-being of insecure workers. Their analyses revealed evidence of what they interpreted as a 'social norm' effect for aggregate unemployment: male insecure workers who lived in regions more adversely affected by unemployment reported higher life satisfaction than insecure workers residing in areas with lower unemployment rates. Other research has found no influence of aggregate unemployment on the experiences of insecure workers (Flint et al. 2013). However, the contradictory findings of the Clark et al. (2010) and Lam et al. (2013) studies could be 
potentially a consequence of national labor market or welfare state differences, or the different measures of well-being utilized; but it may also be due to the inability of Lam's and colleagues' (2013) study to accurately model variations in economic context, given that they had access to only two labor market periods (those of 2006 and 2010).

\section{Amplified Threat or Relative Comparison? Competing Hypotheses}

To understand how labor market conditions might influence individuals' reactions to job insecurity, we start with the proposition that experiences of threat and uncertainty encourage individuals to seek environmental and contextual factors as points of evaluation (Darley and Latané 1968; Festinger 1954; Wills 1981). External factors, including the experiences and behaviors of others, represent sources of information that can be used by an individual to evaluate the nature of their predicament, their level of culpability, and potential solutions. We pose two competing hypotheses about how individuals use information pertaining to labor market conditions when they are faced with the threat of job loss.

The Amplified Threat Hypothesis: One possibility is that workers facing a threat to their current employment may use the experiences of those around them to assess the resources and opportunities available to them in the event of job loss. In this light, poor labor market conditions characterized by high unemployment should signal fewer opportunities for reemployment, thus heightening the consequences and worry that workers attach to the threat of job loss-a prediction that has been supported by Lam and colleagues (2013) with regard to American insecure workers before and after the Great Recession. Accordingly, the amplified threat hypothesis predicts that the association between job insecurity and poorer mental health should be strongest for individuals residing in regions with higher levels of unemployment. Conversely, job insecurity should be less consequential for mental health in favorable economic climates, 
since the fear of being unable to find reemployment in the event of job loss should be dampened in these contexts.

The Social Norm of Insecurity Hypothesis: Alternatively, we draw from social comparison theory (Festinger 1954) and literature on collective social support, to predict that the stress of job insecurity should be lowest when unemployment levels are high. In alignment with Clark et al.'s (2010) previous work, we refer to this hypothesis as the social norm of insecurity hypothesis.

A key tenet of social comparison theory is that individuals facing a threat are more likely to compare themselves to surrounding others in an effort to retain a positive self-image (Buunk 1994; Festinger 1954). Moreover, comparisons to similar others may normalize the situation, making the stressor less salient, and therefore less detrimental (Wheaton et al. 2012; Young and Wheaton 2013). Poor labor market contexts may also make it easier for self-enhancing downward comparisons with others less fortunate (i.e. the unemployed) (Wills 1981). Early studies examining the causes and consequences of downward social comparisons revealed that cancer and arthritis patients were more likely to engage in comparisons with those who were perceived as worse-off (DeVellis et al. 1991; Wood, Taylor, and Lichtman 1985). Such strategies have been demonstrated to have benefits for improving well-being, especially for those under stress or with low self-esteem (Gibbons 1986). It is therefore possible that insecure workers may engage in similar coping strategies in an effort to protect and restore a positive self-image - and this should be most feasible when unemployment is more prevalent.

A second, related explanation incorporates the notion of collective social support: As noted previously, individuals surrounded by similar others may assume a sense of shared empathy, emotional support, and generalized social support (Pillemer and Suitor 1996; Suitor 
and Keeton 1997). This presumed support should help mitigate the consequence of the stressor in question (Lin et al. 1999; Young and Wheaton 2013) - in this case, the psychological consequences of job insecurity. Given that perceptions of job insecurity among the employed are common during periods of high unemployment, the experience of job insecurity is most likely to be considered by individuals as shared and normal in these circumstances. Consequently, insecure individuals in high unemployment contexts should be more likely to perceive greater collective social support, which should alleviate some of the stress associated with their threatened situation.

Based on the above arguments, the social norm of insecurity hypothesis predicts that the positive association between job insecurity and poorer mental health should be weakest for individuals residing in regions with high levels of unemployment. Due to limitations of our data, we cannot test social comparison processes or perceived social support directly. Rather, we theorize that these mechanisms influence the psychological outcomes of insecure workers in higher versus low unemployment areas.

\section{Intervening Processes: Psychological Resource Erosion}

We hypothesize that the aforementioned mechanisms will influence insecure workers' mental health directly, but also indirectly -by reducing the psychological resources individuals might otherwise rely upon to ameliorate the threat and consequences of job insecurity. We draw from the Stress Process Model (Pearlin 1999) to examine the extent that the erosion of certain psychological resources—-specifically feelings of personal mastery—accounts for the stress experienced by insecure workers. Numerous studies have shown that mastery-the degree that an individual believes they have control over meaningful events and circumstances of their liferepresents an important psychological resource for fostering and protecting mental health 
(Mirowsky and Ross 2003). However, recent research suggests that these beliefs may be undermined by prolonged insecure work experiences (Glavin 2013), depriving individuals of their associated mental health benefits. Other research highlights that context-specific disadvantage, such as economic decline and prevalence of unemployment may also reduce psychological resources (Ross, Mirowsky and Pribesh 2001). As part of our tests of the amplified threat and social norm hypotheses, we therefore conduct mediation analyses to consider whether personal mastery beliefs are (1) disproportionately eroded by job insecurity across different labor market contexts, and (2) whether reduced feelings of mastery contribute to any mental health patterns that we find with regard to job insecurity experiences.

\section{DATA AND METHOD}

Sample. We use individual-level and census division-level data to test our hypotheses. Our individual data are from the 2011 Canadian Work Stress and Health study (CAN-WSH), a national survey of the Canadian labor force. Interviews were conducted by telephone between January and August 2011. To be eligible to participate in the study, individuals had to be: (1) residing in Canada, (2) 18 years of age or older, (3) currently working at a paid job or operating an income-producing business, (4) employed in the civilian labor force, and (5) live in a noninstitutional residence. In households with more than one eligible person, we used the "next birthday" method to randomly select a study participant. Calls were made to a regionally stratified unclustered random probability sample generated by random-digit-dial methods. Interviews were conducted in English or French and averaged approximately 30-35 minutes. Study participants received a $\$ 20$ gift card for completing the interview. The final full sample included 6,004 participants, and was weighted by gender, age, marital status, and education according to distributions in the 2006 Canadian Census. The response rate was approximately 40 
percent. We exclude the self-employed and respondents missing answers on our focal items (final sample, $\mathrm{n}=3,900){ }^{1}$

\section{Focal Individual-level Measures}

Psychological distress. We use seven items of generalized psychological distress from the K10 index developed by Kessler and colleagues (2002) and used in recently published research (Young and Schieman 2012). These items ask about the frequency of the following symptoms in the past month: "anxious or tense," "nervous," "worry a lot about little things," "had trouble keeping your mind on what you were doing," "restless or fidgety," "sad or depressed," and "hopeless." Response choices are "all of the time" (1), "most of the time" (2), "some of the time" (3), "a little of the time" (4), and "none of the time" (5). We reverse-coded these responses and averaged the items to create the index; higher scores indicate greater levels of psychological distress $(\alpha=.83)$.

Psychological resources. We examine psychological resources using a common measure of “mastery": Pearlin and Schooler's (1978) mastery scale. Participants are asked the extent they agree with the following five statements: "You have little control over the things that happen to you," "There is really no way you can solve some of the problems you have," "You often feel helpless in dealing with problems of life," "Sometimes you feel that you are being pushed around in life," "You can do just about anything you really set your mind to." (R) Response choices included: "Strongly Agree” (1), “Agree” (2), "Disagree” (3), and "Strongly Disagree” (4). Responses were summed and averaged with the remaining five statements; higher scores indicate a higher sense of mastery $(\alpha=.67)$.

Perceived job insecurity. Job insecurity is assessed with the following question: "How likely is it that during the next couple of years will you lose your present job and have to look for 
a job with another employer?" Response choices include: "not at all likely" (1), "not too likely" (2) "somewhat likely" (3), and "very likely" (4). This question has been used in several wellrespected surveys including the General Social Survey and the National Study of the Changing Workforce. We combine and contrast respondents in the latter two categories, "somewhat likely" and "very likely" (1), to respondents who answered "not at all likely" or "not too likely" (0). This question was asked of wage and salaried workers, only.

College educated is coded as a dummy variable, where we combine and compare "less than high school", "high school or GED" (reference category) to those with "some college", "associate degree", "four-year college degree", or "graduate or professional degree."

- Gender was coded 1 for women and 0 for men.

- Respondent's age is coded in years. We also test for a non-linear effect of age when estimating both insecurity and distress.

\section{Individual-Level Control Measures}

Our analyses control for a variety of social, work- and family-related conditions.

- Race/ethnicity. We compare respondents who are white to all other ethnic categories.

- One item assesses total personal earnings in the previous year-from all sources. We used the following categories: “\$25,000 or less,” “\$25,001 to $\$ 50,000$, , “\$50,001 to $\$ 75,000$, " “\$75,001 to $\$ 100,000, "$ " $\$ 100,001$ or more." We use the modal category $(\$ 25,001$ to $\$ 50,000)$ as the reference group.

- Occupation To assess respondents' occupation, the following question was asked: "What kind of work do you do? That is, what is your occupation?" Using the open-ended information provided, occupations are coded into thirty-three categories using the 2006 Canadian National Occupation Classification. Codes are collapsed into seven main categories in accordance with 
the 1990 US census standard occupational classification system. These include "executive" (the reference category), "professional," "technical," "service," "sales," "administrative” and "production" occupations.

- Work hours We model work hours as a continuous measure, based on respondents' reports of the number of hours they typically work at their main job per week. Work sector. We compare respondents working in the for-profit sector to government and non-profit.

- Number of children was measured using a count of children under 18 living at home.

- Marital status We compared married respondents to those divorced, widowed, cohabitating, or never married

\section{Census Division-Level Data}

We linked all personal interviews to the 2011 Canadian Census Division data, available through Statistics Canada. Census divisions reflect the second-level of geographic designation or unit in Canada (the first being the broader province or territory). Census division boundaries are set depending on provincial or territorial regulation, and might comprise a county, municipality or regional district. In areas where census division laws do not exist, Statistics Canada has formally designated comparable division boundaries, in correspondence with the province/territory, for the purpose of data collection (Statistics Canada 2011:

http://www12.statcan.gc.ca/census-recensement/2011/ref/dict/geo008-eng.cfm). ${ }^{2}$ Census divisions are the most appropriate level-2 unit for our purposes, especially compared to other geographical delineators, such as census tracts or provinces. Census divisions are sufficiently large, which allows for greater detection of variations between regions. The boundaries of census tracts might be too small to detect these between-group differences, thereby masking important contextual effects. Moreover, residents are likely more aware of the unemployment rate of their 
general region, as oppose to their immediate census tract of residence, since the former projects labor market opportunities. Census divisions might also be preferable to provincial level demarcations, since employment opportunities and unemployment rates still vary within provinces (Statistics Canada 2011). We effectively capture these variations by referencing census divisions as our level-2 unit of analysis.

The data from census divisions were merged with individual-level data using the 2011 Canadian Postal Code Conversion File (PCCF4F+), which automatically assigns a census division code to each respondent based on their respective residential postal code; a common approach in ecological research (Matheson et al. 2006). We were missing postal codes for several respondents ( $\mathrm{N}=250)$, but were able to impute some of these values from information gathered from the respondents on their residence 18 months after the original interview. Given that several of these respondents may have moved during this time, we only imputed missing postal codes for respondents who had remained at the same place of employment, with the assumption that these respondents remained in the same census division.

At the census division level, we use a measure of average unemployment rates per region with the assumption that higher rates of unemployment will impact the perception of job insecurity and its mental health consequences among residents.

To rule out possible confounding effects, we control for additional census division-level measures of disadvantage, median value of dwelling (in \$10,000) and percent of high school dropouts aged 25 to 64 . We also control for the percent of self-identified Christians in the area, to avoid theoretically and analytically confounding presumed collective social support and potential institutionalized religious support. Finally, we control for the population size of each division to rule out the possibility that population per region may distort our results. We create 
four dummy measures (1) metro population (reference category; greater than 750,000), (2) large population (250,001 to 750,000$)$, (3) medium population (60,001 to 250,000$)$, and (4) small population (60,000 or less). We compare individuals in large, medium, and small populations to those in metropolitan populations (coded 0 ).

\section{ANALYTIC STRATEGY}

To capture the effect of unemployment on perceptions and consequences of job insecurity, we use multilevel modeling techniques (we specify a binary logit model to estimate reports of insecurity, and a linear model to estimate mastery and distress as continuous variables (Raudenbush and Bryk 2002)). By using multilevel modeling, we can simultaneously model individual and region-level predictors of job insecurity and psychological outcomes. The advantage of multilevel modeling is that it divides the total variance in the outcome into portions due to variance strictly between-individuals and variance between regions.

We model our measures of unemployment and census controls as occurring at level 2 or the division level. Perceptions of job insecurity, psychological outcomes, and all other control measures are modeled at the individual-level. First, we regress perceived job insecurity on total unemployment rate (Table 2). In all models, we estimate job insecurity as a dichotomous outcome, and use a binary distribution. We then regress psychological outcomes on the additive and combined effects of job insecurity and unemployment (Tables 3 and 4). Throughout all analyses, we estimate psychological distress and resources as continuous outcomes. The generic distress model at level 1 can be specified as:

$$
\text { Distress }=\beta_{0 j}+\beta_{1 j}\left(\text { Insecure }_{i j}\right)+\boldsymbol{\beta}_{2 j}\left(\text { Controls }_{i j}\right)+e_{i j}
$$

With this at level 2: 


$$
\begin{aligned}
& \beta_{0 j}=\gamma_{00}+\gamma_{01}\left(\text { Unemploy }_{j}\right)+u_{0 j} \\
& \beta_{1 j}=\gamma_{10}+\gamma_{11}\left(\text { Unemploy }_{j}\right)+u_{1 j} \\
& \boldsymbol{\beta}_{2 j}=\boldsymbol{\gamma}_{20}
\end{aligned}
$$

Here, $\gamma_{00}$ is the mean distress level across divisions when all controls are set to mean of the respondent's division. $\gamma_{01}$ is the cross-level effect of division-level unemployment on distress, $\gamma_{10}$ is the coefficient for insecurity, $\gamma_{11}$ reflects the cross-level interaction effect between unemployment and insecurity on distress, $\gamma_{20}$ represents the general coefficients for all individual-level controls. Note that $e_{i j}$ is the individual-level error. When testing the cross-level interactions between unemployment and insecurity we specify a random component for insecurity $\left(u_{1 j}\right)$. A similar formula is used to estimate psychological mastery as an outcome measure. We assume an unstructured covariance between the random model components. We group-mean center all individual-level measures to avoid issues of collinearity across levels, and

to clarify the interpretation of the estimated slope and variance components (see Enders and Tofighi 2007; Raudenbush and Bryk 2002, for detailed discussions of the benefits of group-mean centering compared to other approaches, such as grand-mean centering).

\section{Data Sparseness}

In total, our respondents reside in 279 different divisions, with an average of 15 respondents per division. We do, however, have a few single to two-respondent census divisions ( $\sim 2 \%$ of our sample); yet it is unlikely that these data patterns affect our final analyses. Multilevel modeling techniques are sensitive to data sparseness at the individual-level. Sparse divisions are inversely weighted in the analysis, using the weighted precision estimate for each tract (Raudenbush and Bryk 2002). Thus, one and two-person divisions likely have little influence on the level-2 estimates. Several studies have tested the robustness of multilevel 
regression analyses under varying conditions of sparseness, and find that the number of groups is more important for unbiased estimation than the number of observations per group (Maas and Hox 2004). Evidence using data simulations further suggests that the fixed effects produced by multilevel models are quite robust, even in cases where there are very few observations per level2 unit (Clarke and Wheaton 2007; Maas and Hox 2004).

\section{RESULTS}

Individual and census division-level descriptive statistics for study participants are provided in Table 1. Despite the number of missing cases, our final sample is generally consistent with the broader Canadian population. For example, respondents work on average 38 hours per week and just over half are married, which is consistent with the national average above 18 years of age (ESDC 2015; Statistics Canada 2011). The majority live in either the province of Ontario (40 percent) or Quebec (22 percent), which are the two most populated areas of Canada.

Similar to other national surveys in North America, our sample over-represents higher educated, middle aged women. Sixty-two percent of the sample are women; 64 percent are college educated, and the average age is 44 years old. We correct for these biases by weighting our sample on these characteristics, based on 2006 Canadian Census distributions. Additional details about the sample are presented in Table 1.

\section{Random Patterns of Job Insecurity, Mastery, and Psychological Distress across Divisions}

Prior to predicting job insecurity, mastery and distress, we tested whether there are between-division variations in each outcome. In results not shown, we find significant variation in job insecurity between divisions ( $\tau_{00}=.318, \mathrm{p}<.001$; i.e., area-level variance). This value was 
produced from a multilevel logistic model with a random intercept component and no predictors at either level. We calculate the intraclass correlation (ICC) using this information, based on the latent variable method. According to Merlo and colleagues (2006) the latent variable method transforms the individual-level variance from "a probability scale to [a] logistic scale" (p. 292). The propensity scores of meeting the condition—in our case, reporting insecurity—become the unobserved individual-level variable with a known variance equal to $\pi^{2} / 3$ (or 3.29). The ICC for job insecurity therefore becomes $\mathrm{V}_{\mathrm{A}} / \mathrm{V}_{\mathrm{A}}+\mathrm{V}_{\mathrm{I}}(.318 / .318+3.29=.08)$, where $\mathrm{V}_{\mathrm{A}}$ equals the arealevel variance, and $\mathrm{V}_{\mathrm{I}}$ reflects the individual-level variance. Calculations suggest that approximately eight percent of the variance in respondents' job insecurity is between divisions (see Merlo et al. 2006, for additional details on calculating the ICC for binary outcomes).

We also find significant variation in mastery and distress among respondents across divisions $\left(\tau_{00}=.010, \mathrm{p}<.001 ; \tau_{00}=.012, \mathrm{p}<.001\right.$, respectively). These values were produced using multilevel linear models for each continuous outcome with random intercept components and no predictors at either level (i.e., One Way Analysis of Variance (ANOVA)). The ICC from the ANOVA estimates suggest that approximately 3.7 percent of the variance in respondents' mastery, and three percent of the variance in respondents' distress is between divisions. Despite these modest values, our findings suggest that there are some division-level differences to estimate.

Furthermore, we are less interested in explaining variation in mastery/distress away by level-2 factors than we are in testing the pattern of how level-2 conditions impact the insecuritypsychological distress/resource association. We establish significant variation in the impact of insecurity on our two outcomes across divisions by estimating random slopes models. The random slopes models include job insecurity as a predictor of mastery and distress, respectively, 
and also allow the job insecurity slope to vary between divisions. In each case, the random variance component for job insecurity was significant $\left(\tau_{11 \text {-mastery }}=.021, \mathrm{p}<.05 ; \tau_{11 \text {-distress }}=.033, \mathrm{p}\right.$ $<.05$ ). Job insecurity was the only predictor entered into these models (results available from the authors upon request). In model 1 of Tables 3 and 4, we present the random slope for insecurity after considering additional covariates, and still find significant differences in the effect of insecurity on mastery and distress, respectively $\left(\tau_{11 \text {-mastery }}=.022, \mathrm{p}<.05 ; \tau_{11 \text {-distress }}=.045, \mathrm{p}<.05\right)$. These tests indicate that the effect of job insecurity varies depending on some unspecified division characteristic, and we can proceed to test an interaction between census division unemployment rate and job insecurity predicting mastery and distress. ${ }^{3}$

\section{Results for Perceived Job Insecurity as an Outcome}

Table 2 tests one model to determine whether census division unemployment increases the log odds of reporting job insecurity. Here, we allow the intercept for job insecurity to vary between divisions, and control for (a) our selected census division measures; (b) additional antecedents of job insecurity; and, (c) population size at the census division level. Model 1 shows that unemployment rate at the census division level is positively associated with the log odds of reporting job insecurity $(\mathrm{b}=.118, \mathrm{p}<.05)$. The only other statistically significant census division measure is median dwelling value. Table 2 also presents expected results for our selected covariates on increasing the log odds of perceived job insecurity. While women do not exhibit differences in job insecurity compared to men, age of respondent does seem to matter, but non-linearly. Married respondents are less likely to report insecurity compared to unmarried respondents. Those who are employed in for-profit businesses are more likely to report insecurity compared to those in government or non-profit organizations. Those who earn $\$ 25,000$ or less are more likely to report insecurity compared to those earning $\$ 25,000-50,000$. Whereas those 
who earn more than $\$ 50,000$ each year are less likely to report insecurity compared to those earning $\$ 25,000-50,000$. Finally, whites are less likely to report insecurity compared to nonwhites.

\section{Results for Psychological Resources (Mastery) as an Outcome}

Table 3 tests several models to determine the main effect of insecurity and unemployment rate on psychological resources using our measure of mastery. This allows us to address our focal research question and key hypotheses: does the unemployment rate at the census division level modify the impact of perceived job insecurity on psychological resources for the respondents in our sample? The social norm of insecurity hypothesis predicts that psychological consequences of job insecurity will be less in regions with higher unemployment rates. The amplified threat hypothesis proposes the alternative: Higher rates of unemployment will decrease the psychological benefits of perceived job insecurity. Model 1 shows that job insecurity on its own, controlling for a variety of covariates, is negatively associated with levels of mastery $(b=-.153, p<.001)$. In model 2 we add unemployment rates at the census division level to the equation, and find no additive association between unemployment and mastery.

Model 3 tests our focal hypothesis of whether unemployment rates modify the association between perceived job insecurity and psychological mastery. The result for the interaction term presented in model 3 provides evidence for the social norm hypothesis $(b=.018, p<.05$, $95 \% \mathrm{CI}=.001$ to .036 ), and aligns with ideas of social comparison theory and relative deprivation: we theorize that when individuals compare their circumstances to others in similar situations, they are more likely to embrace a positive self-image, perceive social support, and thereby assume greater psychological resources, or coping devices to help deal with the situation at hand (Festinger 1954; Schachter, 1959; Wills 1981; Young and Wheaton 2013). Subsequent tests confirm significant differences in the impact of job insecurity on mastery in high versus low 
unemployment areas $(F=14.38, \mathrm{p}<.001)$. We present this association visually in Figure 1 where we plot the association between job insecurity and mastery by unemployment rates. Respondents with job insecurity report higher mastery levels in areas with high unemployment compared to low unemployment divisions (represented by the light grey bars). When comparing mastery levels between insecure and secure workers, we can see rather comparable values among those in high unemployment areas, compared to low unemployment areas (light versus dark grey bars).

\section{Results for Psychological Distress as an Outcome}

Table 4 takes a comparable approach to Table 3, using psychological distress as an outcome. We also test whether our focal associations between job insecurity, unemployment rates, and psychological distress are mediated or explained away by acquired levels of mastery. Model 1 shows that job insecurity on its own, controlling for a variety of covariates, is positively associated with distress levels $(\mathrm{b}=.224, \mathrm{p}<.001)$. In model 2 we add unemployment rates at the census division level to the equation, and find no significant association.

Model 3 tests our focal hypothesis of whether unemployment rates modify the association between perceived job insecurity and distress. The result for the interaction term presented in model 3 provides evidence for the social norm hypothesis, suggesting that the mental health consequences of job insecurity are less in areas where the unemployment rate is higher $(b=-.026$, $\mathrm{p}<.05 ; 95 \% \mathrm{CI}=-.049$ to -.003$)$. Subsequent tests confirm significant differences in the impact of job insecurity on mastery in high versus low unemployment areas $(F=6.51, \mathrm{p}<.01)$. This finding supports the social norm hypothesis. We present this association visually in Figure 2 where we plot the association between job insecurity and distress by unemployment rates. Insecure workers in high unemployment areas report less distress compared to insecure workers in low unemployment areas (right versus left-sided light grey bars). 
Model 4—our final model in Table 4 - adds our psychological resource measure (mastery) to the model to see if these acquired coping mechanisms explain part of our moderated association between job insecurity and unemployment on distress. Mastery is negatively associated with distress levels $(-.684, \mathrm{p}<.001)$, and partially mediates, or explains away the interaction effect with distress $\left(b_{\text {ins*unemp-mod } 3}=-.026, p<.05 ; b_{\text {ins*unemp-mod } 4}=-.015, p>.05\right)$. We present this association visually in Figure 3 where we plot the association between job insecurity and distress by unemployment rates, after controlling for mastery levels. Note that the patterns between insecurity and distress by unemployment equalize, suggesting the mastery plays a key role in these associations.

Not only does the statistical significance of the interaction decrease across models, its magnitude also reduces by about half. This suggests that the buffering influence of unemployment rates for job insecurity's distressing consequences may result from the psychological resources it promotes among individuals facing such uncertainty in these climates (evidenced in Table 3). Coupled with the results in Tables 2 through 4, our study provides evidence consistent with the predictions of the social norm hypothesis. We discuss the implications of our findings for research on unemployment, insecurity, and health in context, below.

\section{DISCUSSION}

A growing number of studies have shown that economic recessions impact not only the lives and well-being of those who lose their jobs during these periods, but also those who remain employed but with weakened job security (Burgard 2009; Tausig and Fenwick 2012). In the last two decades, mental health scholars have shown that the anticipation of job loss is associated 
with a variety of negative personal consequences, yet understanding about how contextual factors—especially at the economic level—shape these consequences remains limited. We suggest that the absence of research on this issue is rather surprising: While there has been considerable effort to examine how the mental health consequences of unemployment are dependent upon broader labor market conditions, there have been few attempts to investigate the role of labor market context for the tenuously employed. This dearth of scholarship persists, despite the fact that unemployment is experienced by a minority of individuals when compared against the number of those who consider their jobs at risk (as high as 25 percent among some areas of the workforce). To address this oversight, we use a large, national sample of Canadian workers and investigate whether the stress of job insecurity is contingent on others' labor market experiences-measured using the prevalence of regional unemployment.

Overall, our results suggest that aggregate unemployment influences individuals' psychological reactions to job insecurity in a similar pattern as it shapes the mental health consequences of unemployment. CAN-WSH respondents who live in regions with higher rates of unemployment are more likely to perceive their jobs to be at risk-confirming previous research that individual-level indicators of job insecurity are indeed linked to aggregate labor market signs of insecurity. Critically, however, perceptions of job insecurity are associated with fewer mental health costs for individuals residing in regions most affected by unemployment-a pattern that is consistent with the predictions of the social norm of insecurity hypothesis and recent research on German and South African workers (Clark et al. 2010; Powdthavee 2007.

We have also sought to advance existing research by examining the role of psychological resources (i.e. mastery) in explaining these processes. We find evidence that mastery beliefs mediate the tendency for higher unemployment levels to reduce the stress associated with job 
insecurity. That is, it appears that mastery — as a psychological resource — is less influenced by the threat of job loss in high unemployment contexts, which translates into better mental health for insecure workers in such contexts. It may be the case that mastery partially confounds the association between job insecurity and distress; fluctuations in the two outcomes may occur simultaneously, affecting one another. It is difficult to disentangle these associations without longitudinal data. Nevertheless, we base our theoretical model and analytic strategy on previous studies that suggest reduced mastery results in elevated psychological distress (Pearlin 1999).

We interpret our findings through the lens of social comparison theory (Festinger 1954) and the old adage that 'misery loves company.' It may be that the greater prevalence of unemployment and insecurity, the more common and expected they are seen to be, and thus, the less distressing they are considered when an individual personally encounters them. While a high unemployment rate may signal fewer opportunities for reemployment, job insecure individuals may evaluate their situation relative to others' economic circumstances or some generalized, collective norm, in a way that reduces the stress associated with the experience and allows them to retain a positive self-image. Evidence of social comparison effects have been observed with other forms of chronic stress, including unemployment, work-family conflict, and chronic illness (Clark 2003; Wood et al. 1985; Young and Wheaton 2013).

These comparison processes relate to a second, related mechanism, which might provide psychological benefits to insecure workers in insecure places: perceived collective social support. Similarity in experiences-especially negative experiences - breed a sense of shared empathy and understanding (Pillemer and Suitor 1996; Suitor and Keeton 1997). In the case of our study, we theorize that insecure respondents in contexts of high unemployment not only compare their situation to similar others, but also derive a sense of support from these negative 
commonalities. These processes may then influence psychological outcomes, including resources (mastery), and consequences (distress). While we do not test these processes directly, we theorize our analytical findings of mastery and psychological distress to align with related literature on collective social support processes (Lin et al. 1999; Young and Wheaton 2013)

The conflicting patterns revealed between our study and previous research on the subject necessitates further investigation before stronger assertions can be made with regard to these inconsistencies. Nevertheless, we think it is important to interpret and reconcile the conflicting evidence available thus far. Our analyses and findings most closely approximate Clark and colleagues (2010) study of German panel data. Where we advance on this study is our access to an established measure of psychological distress (the previous study relied on a single-item indicator of 'life satisfaction'). In contrast, the findings of Lam and colleagues (2013) analysis of the American GSS are less consistent with our findings. There are a number of potential explanations for these differences. First, it is possible that the patterns observed by Lam and colleagues were a result of the intense focus on the economy at the time- -within public, media and political spheres — which then imbued the threat of job loss with increased, rather than decreased, significance. Alternatively, given the different national contexts of the three studies, the inconsistent findings may be a product of cultural differences in the meaning and value of employment. It may be that Americans' emphasis on individualism and economic mobility offsets any influence of a social comparison process. A third possible explanation for the discordant findings is that our study did not model within-region change in unemployment rates, but instead between-region differences in unemployment. Thus, it is possible that workers' employment anxieties are actually more sensitive to changes in labor market opportunities rather than as part of an externally rooted comparison process. Nevertheless, we see our findings as 
best fitting a social comparison model — although further empirical investigation is vital before stronger conclusions can be made.

We briefly discuss a number of limitations associated with our study. As noted above, our analyses testing a link between perceived job insecurity and psychological outcomes could be further strengthened by the inclusion of longitudinal panel data. This would enable more sophisticated techniques for establishing causality. In the absence of panel data, we rely on previous empirical research on job insecurity that has revealed evidence of a temporal ordering that is consistent with our interpretations of the job insecurity-distress patterns revealed in our analyses (Clark et al. 2010; Ferrie et al. 1995). Data sparseness might also compromise some of our results. Yet, we are confident that these data patterns do not affect our final analyses, since sparse divisions are inversely weighted in the analysis, using the weighted precision estimate for each tract (Raudenbush and Bryk 2002). Nevertheless, we acknowledge that more populated divisions would be ideal.

Additionally, while we use an established measure that taps into the perceived risk of job loss, additional research should investigate how labor market contexts might shape the mental health consequences of workers' affective responses to future job loss. Beyond cognitive appraisals of insecurity, affective responses to the threat of job loss are likely to vary depending on a worker's financial or family circumstances, or even their access to welfare services. Little is known about how affective insecurity responses operate in high unemployment contexts; however, it is possible that workers who worry deeply about losing their job are less comforted when the experience is normative - a possibility that we believe deserves further investigation.

\section{CONCLUSION}

In this paper, we questioned whether uncertain employment conditions are associated 
with fewer psychological consequences when living around others who occupy similar or worse economic positions. We find that workers who live in areas most affected by unemployment are more likely to perceive a threat to their continuing employment; yet our analyses show that the stress associated with this perceived threat is lower within high unemployment contexts, perhaps because when surrounding others are enduring equally or more difficult times, there is a sense of comfort and support knowing that one is not alone with respect to their hardship. This is not to underplay, however, the experiences of the disadvantaged workers that encounter these labor market conditions. Such workers deal with the challenge of financial uncertainty on a daily basis, and are most vulnerable to economic downturns due to their tendency to be employed in sectors of the labor market that are most sensitive to economic change. Future research should therefore investigate how the mental health consequences of insecure work are shaped also by specific worker locations in the economy, and how these locations might interact with broader economic change to produce heath disparities. We make a call for further research that connects large, national survey samples of workers to econometric data in order to better understand the interconnections between economic conditions and the stress of precarious work. 


\section{NOTES}

1. Some readers might have concerns about our response rate. Although a potential problem associated with lower response rates is nonresponse bias in estimates (Babbie 2007), recent research has challenged the link between response rates and nonresponse bias (Curtin, Presser, and Singer 2000; Merkle and Edelman 2002). Nevertheless, we address the possibility that results were unduly influenced by nonresponse bias. In order to do this, we compared results from unweighted and weighted analyses in which we weighted the sample based on a key set of demographic statuses (e.g., gender, age, marital status, education) from the 2006 Canadian Census. We found few differences between the weighted and unweighted results. Winship and Radbill (1992) argue that controlling for characteristics on which individuals may be under- or over-sampled adjusts for biases due to these characteristics; all of our analyses include a set of controls to adjust for this potentiality.

2. We tested our associations using unemployment rates from census subdivisions, as well. Subdivisions refer to smaller geographical areas, and often reflect governmentdefined municipalities or some equivalent area. Results were generally comparable across the two sets of analyses. We decided to use census divisions instead of subdivisions, however, for two reasons. The first reason is methodologically-based: the number of respondents per group decreases substantially when we use subdivisions compared to divisions, since subdivisions reflect smaller geographical areas. Second, we assume - theoretically — that unemployment rates will have a greater impact at the more general, rather than local level. That is, unemployment 
rates reflect broader macro-level economic conditions that impact large geographical areas and the people within them.

3. We also examined the empirical bayes job insecurity slopes across divisions for mastery and distress. The empirical bayes slopes comprise the fixed and random effects for each separate geographical area. For the sake of space, we do not list all of the slopes, but provide example cases in Appendix A. These estimates are based on models excluding all control variables. 


\section{REFERENCES}

Babbie, Earl. 2007. The Practice of Social Research, 11th edition. Belmont, CA: Wadsworth.

Brenner, Harvey M. 1973. Mental Illness and the Economy. Harvard U. Press.

Buunk, Bram P. 1994. "Social Comparison Processes Under Stress: Towards an Integration Of Classic And Recent Perspectives." European Review of Social Psychology 5:211-241.

Burgard, Sarah A., Jennie Brand, and James S. House. 2009. "Perceived Job Insecurity and Worker Health in the United States.” Social Science \& Medicine 69:777-785.

Clark, Andrew E. 2003. "Unemployment as a Social Norm: Psychological Evidence from Panel Data." Journal of Labor Economics 21(2):323-351.

Clark, Andrew, Andreas Knabe, and Steffen Rätzel. 2010. "Boon or Bane? Others' Unemployment, Well-being and Job Insecurity.” Labour Economics 17:52-61.

Clarke, Philippa, and Blair Wheaton. 2007. “Addressing data sparseness in contextual population research using cluster analysis to create synthetic neighborhoods." Sociological Methods \& Research 35(3):311-351.

Curtin, Richard, Stanley Presser, and Eleanor Singer. 2000. “The Effects of Response Rate Changes on the Index of Consumer Sentiment." Public Opinion Quarterly 64:413-28.

Darley, John M. and Bibb Latané. 1968. "Bystander Intervention in Emergencies: Diffusion of Responsibility." Journal of Personality and Social Psychology 8:377-383.

DeVellis, Robert F., Susan J. Blalock, Kathleen Holt, Barbara Rochen Renner, Lynn W. Blanchard, and Mary Lou Klotz. 1991. “Arthritis Patients' Reactions to Unavoidable Social Comparisons." Personality and Social Psychology Bulletin 17:392-399. 
Enders, Craig K. and Davood Tofighi. 2007. "Centering Predictor Variables in Cross-Sectional Multilevel Models: A New Look at an Old Issue.” Psychological Methods 12(2):121138.

Farber, Henry S. 2010. "Job Loss and the Decline of Job Security in the United States." Pp. 223267 in Labor in the New Economy edited by Katherine Abraham, James Spletzer and Michael Harper. University of Chicago Press, Chicago.

Fenwick, Rudy and Mark Tausig. 1994. "The Macroeconomic Context of Job Stress.” Journal of Health and Social Behavior 35:266-282.

Ferrie, Jane Elizabeth, Martin John Shipley, Michael Gideon Marmot, Stephen Alfred Stansfeld, and George Davey Smith. 1995. "Health Effects of Anticipation of Job Change and Nonemployment: Longitudinal Data from the Whitehall II Study." British Medical Journal 311:1264-1269.

Festinger, Leon. 1954. “A Theory of Social Comparison Processes.” Human Relations 7(2):117140.

Flint, Ellen, Nicola Shelton, Mel Bartley, and Amanda Sacker. 2013. "Do Local Unemployment Rates Modify The Effect Of Individual Labour Market Status On Psychological Distress?" Health \& Place 23:1-8.

Fullerton, Andrew S. and Michael Wallace. 2007. "Traversing the Flexible Turn: US Workers' Perceptions of Job Security, 1977-2002." Social Science Research 36:201-221.

Fullerton, Andrew S. and Kathryn F. Anderson. 2013. "The Role of Job Insecurity in Explanations of Racial Health Inequalities." Sociological Forum 28:308-325.

Gibbons, Frederick X. 1986. “Social Comparison and Depression: Company's Effect On Misery." Journal of Personality and Social Psychology 51:140-148. 
Glavin, Paul. 2013. "The Impact of Job Insecurity and Job Degradation on the Sense of Personal Control." Work and Occupations 40:115-142.

Glavin, Paul. 2015. “Perceived Job Insecurity and Health: Do Duration and Timing Matter?” The Sociological Quarterly 56(2):300-328.

Hill, Terrence and David Maimon. 2013. "Neighborhood Context and Mental Health.” Pp. 479-501 in Handbook of the Sociology of Mental Health, edited by C. Aneshensel, A. Bierman, and J. Phelan. New York: Springer.

Jackson, Paul and Peter Warr. 1987. "Mental Health of Unemployed Men in Different Parts Of England And Wales.” British Medical Journal 295:525.

Jahoda, Marie. 1982. Employment and Unemployment: A Social Psychological Analysis. New York: Cambridge University Press.

Kalleberg, Arne. 2009. "Precarious Work, Insecure Workers: Employment Relations in Transition.” American Sociological Review 74:1-22.

Kawachi, Ichiro and Lisa F. Berkman, L. F. (Eds.). 2003. Neighborhoods and Health. Oxford: Oxford University Press.

Kessler, Ronald C., Gavin Andrews, Lisa J. Colpe, Eva Hiripi, Daniel K. Mroczek, S-LT Normand, Ellen E. Walters, and Alan M. Zaslavsky. 2002. "Short Screening Scales to Monitor Population Prevalences and Trends In Non-Specific Psychological Distress." Psychological Medicine 32:959-976.

Lam, Jack, Wen Fan, and Phyllis Moen. 2014. "Is Insecurity Worse for Well-being in Turbulent Times? Mental Health in Context." Society and Mental Health 4:55-73. 
Lazarus, Richard S. and Susan Folkman. 1984. Stress, Appraisal, and Coping. New York: Springer.

Lin, Nan, Xiaolan Ye, and Walter M. Ensel. 1999. "Social Support and Depressed Mood: A Structural Analysis." Journal of Health and Social Behavior 40:344-359.

Maas, Cora J.M. and Joop J. Hox. 2004. "Robustness Issues in Multilevel Regression Analysis." Statistica Neerlandica 58:127-137.

Matheson, Flora I., Rahim Moineddin, James R. Dunn, Maria Isabella Creatore, Piotr Gozdyra, and Richard H. Glazier. 2006. "Urban Neighborhoods, Chronic Stress, Gender and Depression." Social Science \& Medicine 63:2604-2616.

Merkle, Daniel, and Murray Edelman. 2002. "Nonresponse in Exit Polls: A Comprehensive Analysis.” Pp. 243-258 in Survey Nonresponse, edited by R.M. Groves, D. A. Dillman, J. L. Eltinge, and R. J. A. Little, New York: Wiley Press.

Merlo, Juan, Basile Chaix, Henrik Ohlsson, et al. 2006. "A Brief Conceptual Tutorial of Multilevel Analysis in Social Epidemiology: Using Measures Of Clustering In Multilevel Logistic Regression to Investigate Contextual Phenomena.” Journal of Epidemiological Community Health 60:290-297.

Mirowsky, John and Catherine E. Ross. 2003. Social Causes of Psychological Distress. Hawthorne, New York: Aldine De Gruyter.

O'Campo, Patricia and James R. Dunn. 2012. Rethinking Social Epidemiology. Springer. Pearlin, Leonard I. 1999. “The Stress Process Revisited: Reflections on Concepts and Their Interrelationships." Pp. 395-415 in The Handbook of the Sociology of Mental Health, edited by C. S. Aneshensel and J. C. Phelan. New York: Kluwer Academic/Plenum. 
Pearlin, Leonard I., and Carmi Schooler. 1978. "The Structure of Coping.” Journal of Health and Social Behavior 19:2-21.

Pillemer, Karl and Jill Suitor. 1996. "“It Takes One to Help One’: Effects of Similar Others on the Well-being of Caregivers." The Journals of Gerontology 51B(5):S250-57.

Platt, Stephen, Rocco Micciolo, and Michele Tansella. 1992. "Suicide and Unemployment in Italy: Description, Analysis and Interpretation of Recent Trends.” Social Science \& Medicine 34:1191-1201.

Platt, Stephen and Norman Kreitman. 1990. "Long Term Trends in Parasuicide and Unemployment in Edinburgh, 1968-87." Social Psychiatry and Psychiatric Epidemiology 25:56-61.

Powdthavee, Nattavudh. 2007. "Are There Geographical Variations in the Psychological Cost of Unemployment in South Africa?" Social Indicators Research 80(3):629-652.

Quinlan, Michael and Philip Bohle. 2009. “Overstretched And Unreciprocated Commitment: Reviewing Research On The Occupational Health And Safety Effects Of Downsizing And Job Insecurity." International Journal of Health Services 39:1-44.

Raudenbush, Stephen W. and Anthony S. Bryk. 2002. Hierarchical Linear Models: Applications and Data Analysis Methods. Sage: London.

Ross, Catherine E., John Mirowsky, and Shana Pribesh. 2001. "Powerlessness and the Amplification of Threat: Neighborhood Disadvantage, Disorder, and Mistrust.” American Sociological Review 66:568-91.

Schachter, Stanley. 1959. The Psychology of Affiliation. Stanford. Stanford University Press. Suitor, Jill J. and Shirley Keeton. 1997. "Once a Friend, Always a Friend? Effects of Homophily on Women’s Support Networks across A Decade.” Social Networks 19:51-62. 
Sverke, Magnus and Johnny Hellgren. 2002. "The Nature of Job Insecurity: Understanding Employment Uncertainty On The Brink Of A New Millennium.” Applied Psychology $51: 23-42$.

Tausig, Mark and Rudy Fenwick. 1999. "Recession and Well-being." Journal of Health and Social Behavior 40:1-16.

Tausig, Mark and Rudy Fenwick. 2012. Work and Mental Health in Social Context. Springer. New York.

Wheaton, Blair. 1999. "Social Stress." Pp. 277-300 in The Handbook of the Sociology of Mental Health, edited by C. S. Aneshensel and J. C. Phelan. New York: Kluwer Academic/Plenum Publishers.

Wheaton, Blair, Marisa Young, Shirin Montazer and Catherine Stuart. 2012. "Social Stress in the 21 st Century.” Pp. 299-324 in Handbook of the Sociology of Mental Health, edited by C. Aneshensel, J. Phelan, A. Bierman. 2nd Edition. New York: Springer.

Wills, Thomas A. 1981. "Downward Comparison Principles in Social Psychology." Psychological Bulletin 90:245-271.

Winship, Christopher and Robert D. Mare. 1992. "Models for Sample Selection Bias.” Annual Review of Sociology 18:327-50.

Wood, Joanne V., Shelley E. Taylor, and Rosemary R. Lichtman. 1985 “Social Comparison In Adjustment To Breast Cancer." Journal Of Personality And Social Psychology 49:11691183.

Young, Marisa and Scott Schieman. 2012. "'When Hard Times Take a Toll: The Distressing Consequences of Economic Hardship and Life Events within the Family-work Interface." Journal of Health and Social Behavior 53:84-98. 
Young, Marisa and Blair Wheaton. 2013. "The Impact of Neighborhood Composition on WorkFamily Conflict and Distress." Journal of Health and Social Behavior 54(4):481-497. 
Table 1 Descriptive Statistics for All Study Measures $(N=3,900)$

\begin{tabular}{|c|c|c|c|c|}
\hline \multirow[b]{2}{*}{ Variable } & \multicolumn{4}{|c|}{ Full Sample } \\
\hline & Mean & $\mathrm{SD}$ & Min & Max \\
\hline \multicolumn{5}{|l|}{ Focal Measures } \\
\hline Psychological distress & 2.18 & .71 & 1 & 5 \\
\hline Perceived job insecurity & .22 & - & 0 & 1 \\
\hline Mastery & 2.96 & .53 & 1 & 4 \\
\hline Unemployment rate (cen. div.) & 7.80 & 2.40 & 3.10 & 33.80 \\
\hline Median value of dwelling $(\$ 100,000)$ (cen. div.) & 1.99 & .92 & .30 & 6.10 \\
\hline$\%$ high school dropouts aged 25 to 64 (cen. div.) & 19.10 & 8.40 & 5 & 57 \\
\hline Percent of self-identified Christians (cen. div.) & 77.82 & 15.03 & 37 & 99 \\
\hline \multicolumn{5}{|l|}{ Control Measures } \\
\hline Women & .62 & - & 0 & 1 \\
\hline Age & 43.78 & 11.50 & 18 & 80 \\
\hline College educated & .64 & - & 0 & 1 \\
\hline Married & .51 & - & 0 & 1 \\
\hline Number of children & .78 & - & 0 & 3 \\
\hline Government position & .37 & - & 0 & 1 \\
\hline Non-profit business & .07 & - & 0 & 1 \\
\hline For-profit business & .55 & - & 0 & 1 \\
\hline$\$ 25,000$ or less & .18 & - & 0 & 1 \\
\hline$\$ 25,001$ to $\$ 50,000$ & .34 & - & 0 & 1 \\
\hline$\$ 50,001$ to $\$ 75,000$ & .22 & - & 0 & 1 \\
\hline$\$ 75,001$ to $\$ 100,000$ & .14 & - & 0 & 1 \\
\hline More than $\$ 100,000$ & .04 & - & 0 & 1 \\
\hline Work hours & 38.00 & 11.45 & 2 & 126 \\
\hline White & .86 & - & 0 & 1 \\
\hline Executive & .09 & - & 0 & 1 \\
\hline Professional & .32 & - & 0 & 1 \\
\hline Service & .13 & - & 0 & 1 \\
\hline Sales & .07 & - & 0 & 1 \\
\hline Administrative & .10 & - & 0 & 1 \\
\hline Production & .13 & - & 0 & 1 \\
\hline Technical & .16 & - & 0 & 1 \\
\hline Ontario & .40 & - & 0 & 1 \\
\hline Atlantic & .07 & - & 0 & 1 \\
\hline Quebec & .22 & - & 0 & 1 \\
\hline Alberta & .11 & - & 0 & 1 \\
\hline Prairies & .07 & - & 0 & 1 \\
\hline British Columbia & .13 & - & 0 & 1 \\
\hline Metro population (cen. div.) & .33 & - & 0 & 1 \\
\hline Large population (cen. div.) & .25 & - & 0 & 1 \\
\hline Medium population (cen. div.) & .30 & - & 0 & 1 \\
\hline Small population (cen. div.) & .12 & - & 0 & 1 \\
\hline No. of people per (cen. div.) & 15.12 & 31.59 & 1 & 239.00 \\
\hline
\end{tabular}

Notes: Proportions presented for categorical variables. All descriptives based on unweighted data. 
Table 2 Perceived Job Insecurity Regressed on Unemployment Rate and Selected Covariates $(N=3,900)$

\begin{tabular}{|c|c|c|}
\hline \multirow{2}{*}{ Focal Variables } & \multicolumn{2}{|c|}{ Model 1} \\
\hline & & \\
\hline Unemployment rate (cen. div.) & $.118^{* * *}$ & $*(.030)$ \\
\hline Median $\$$ of dwelling $(100,000)$ (cen. div.) & $.015^{* * *}$ & $*(.005)$ \\
\hline$\%$ HS dropouts, 25 to 64 (cen. div.) & -.021 & $(.015)$ \\
\hline \% Christians (cen. div.) & .014 & $(.010)$ \\
\hline \multicolumn{3}{|l|}{ Control Measures } \\
\hline Women & -.094 & $(.087)$ \\
\hline Age & $.064 * *$ & $(.022)$ \\
\hline Age squared & $-.001 * *$ & $(.001)$ \\
\hline College educated $^{a}$ & -.156 & $(.091)$ \\
\hline Married ${ }^{b}$ & $-.345^{* *}$ & $(.098)$ \\
\hline Number of children & -.036 & $(.044)$ \\
\hline For-profit business ${ }^{c}$ & $.414^{* * *}$ & $*(.094)$ \\
\hline$\$ 25,000$ or less $^{d}$ & $.370^{* * *}$ & $*(.111)$ \\
\hline$\$ 50,001$ to $\$ 75,000^{d}$ & $-.706 * * *$ & $*(.123)$ \\
\hline$\$ 75,001$ to $\$ 100,000^{d}$ & $-.949 * * *$ & $*(.162)$ \\
\hline$\$ 100,001$ to $\$ 125,000^{d}$ & $-.671 * *$ & $(.256)$ \\
\hline More than $\$ 125,000^{d}$ & $-.806 * *$ & $(.255)$ \\
\hline Work hours & -.001 & $(.001)$ \\
\hline Professional $^{e}$ & .066 & $(.168)$ \\
\hline Service $^{e}$ & -.056 & $(.184)$ \\
\hline Sales $^{e}$ & -.104 & $(.201)$ \\
\hline Administrative $^{e}$ & -.248 & $(.201)$ \\
\hline Production $^{e}$ & .062 & $(.180)$ \\
\hline Technical $^{e}$ & -.007 & $(.180)$ \\
\hline White & $-.248 *$ & $(.107)$ \\
\hline Atlantic $^{f}$ & -.377 & $(.242)$ \\
\hline Quebec $^{f}$ & .043 & $(.200)$ \\
\hline Alberta ${ }^{f}$ & .210 & $(.219)$ \\
\hline Prairies $^{f}$ & -.138 & $(.251)$ \\
\hline British Columbia $^{f}$ & -.022 & $(.265)$ \\
\hline Large population $^{g-}$ & .146 & $(.222)$ \\
\hline Medium population ${ }^{g}$ & .277 & $(.243)$ \\
\hline Small population $^{g}$ & .370 & $(.286)$ \\
\hline Fixed intercept & $-4.525 * * *$ & $*(1.031)$ \\
\hline
\end{tabular}

\section{Random Effects}

Insecurity intercept $\left(\hat{\sigma}_{u}^{2}\right)$

$.094^{*}$

${ }^{\dagger} \mathrm{p}<.10, * \mathrm{p}<.05, * * \mathrm{p}<.01, * * * \mathrm{p}<.001$ (two-tailed test).

Notes: Unstandardized logistic coefficients reported from multilevel analyses. Standard errors presented in parentheses. ${ }^{a}$ Compared to all other levels of education. ${ }^{b}$ Compared to cohabiting, single, and previously married. ${ }^{c}$ Compared to private or government workers. ${ }^{d}$ Compared to $\$ 25,001$ to $\$ 50,000 .{ }^{e}$ Compared to Executives. ${ }^{f}$ Compared to Ontario. ${ }^{g}$ Compared to a metro population. 
Table 3 Mastery Regressed on Perceived Job Insecurity, Unemployment Rates, and Selected

Covariates $(N=3,900)$

\begin{tabular}{|c|c|c|c|c|c|c|}
\hline \multirow{2}{*}{ Focal Variables } & \multicolumn{2}{|c|}{ Model 1} & \multicolumn{2}{|c|}{ Model 2} & \multicolumn{2}{|c|}{ Model 3} \\
\hline & & & & & & \\
\hline Job insecurity & $-.153 * * *$ & $(.027)$ & $-.153 * * *$ & $(.035)$ & $-.306 * * *$ & $(.078)$ \\
\hline Unemployment rate (cen. div.) & - & & .015 & $(.005)$ & .014 & $(.005)$ \\
\hline Median $\$$ of dwelling $(100,000)$ (cen. div). & - & & $.014 * * *$ & $(.001)$ & $.017 * * *$ & $(.001)$ \\
\hline$\%$ HS dropouts, 25 to 64 (cen. div). & - & & .001 & $(.003)$ & .001 & $(.003)$ \\
\hline$\%$ Christians (cen. div). & - & & -.002 & $(.001)$ & -.003 & $(.001)$ \\
\hline \multicolumn{7}{|l|}{ Interaction Term } \\
\hline Job insecurity $\mathrm{x}$ unemp. rate & - & & - & & $.018^{*}$ & $(.009)$ \\
\hline \multicolumn{7}{|l|}{ Control Measures } \\
\hline Women & .026 & $(.019)$ & .024 & $(.019)$ & .024 & $(.019)$ \\
\hline Age & $-.005 * * *$ & $(.001)$ & $-.005 * * *$ & $(.001)$ & $-.005 * * *$ & $(.001)$ \\
\hline Age squared & $.001 * * *$ & $(.001)$ & $.001 * * *$ & $(.001)$ & $.001 * * *$ & $(.001)$ \\
\hline College educated $^{a}$ & .004 & $(.020)$ & .004 & $(.020)$ & .006 & $(.020)$ \\
\hline Married $^{b}$ & $.071 * * *$ & $(.020)$ & $.067 * * *$ & $(.020)$ & $.067 * * *$ & $(.020)$ \\
\hline Number of children & -.015 & $(.009)$ & -.015 & $(.009)$ & -.015 & $(.009)$ \\
\hline For-profit business $^{c}$ & -.020 & $(.019)$ & -.020 & $(.019)$ & -.020 & $(.019)$ \\
\hline$\$ 25,000$ or less $^{d}$ & $-.074 * *$ & $(.026)$ & $-.072 * *$ & $(.026)$ & $-.078 * *$ & $(.026)$ \\
\hline$\$ 50,001$ to $\$ 75,000^{d}$ & $.080 * * *$ & $(.024)$ & $.078 * * *$ & $(.024)$ & $.077 * * *$ & $(.024)$ \\
\hline$\$ 75,001$ to $\$ 100,000^{d}$ & $.170^{*}$ & $(.030)$ & $.163^{*}$ & $(.030)$ & $.162 *$ & $(.030)$ \\
\hline$\$ 100,001$ to $\$ 125,000^{d}$ & $.179 * *$ & $(.049)$ & $.174 * *$ & $(.049)$ & $.173 * *$ & $(.049)$ \\
\hline More than $\$ 125,000^{d}$ & $.220 * *$ & $(.048)$ & $.218^{* *}$ & $(.048)$ & $.217^{* *}$ & $(.048)$ \\
\hline Work hours & -.001 & $(.001)$ & -.001 & $(.001)$ & -.001 & $(.001)$ \\
\hline Professional $^{e}$ & $-.068^{*}$ & $(.033)$ & $-.068^{*}$ & $(.033)$ & $-.068 *$ & $(.033)$ \\
\hline Service $^{e}$ & -.074 & $(.038)$ & -.077 & $(.033)$ & -.075 & $(.038)$ \\
\hline Sales $^{e}$ & $-.115 * *$ & $(.043)$ & $-.121 * *$ & $(.043)$ & $-.122 * *$ & $(.043)$ \\
\hline Administrative $^{e}$ & $-.127 * *$ & $(.041)$ & $-.130 * *$ & $(.041)$ & $-.130 * *$ & $(.041)$ \\
\hline Production $^{e}$ & $-.086^{*}$ & $(.049)$ & $-.092 *$ & $(.037)$ & $-.091 *$ & $(.037)$ \\
\hline Technical $^{e}$ & -.012 & $(.050)$ & -.015 & $(.037)$ & -.015 & $(.037)$ \\
\hline White & $.076 * *$ & $(.024)$ & $.080 * *$ & $(.024)$ & $.079 * *$ & $(.024)$ \\
\hline Atlantic $^{f}$ & .025 & $(.043)$ & -.030 & $(.048)$ & -.027 & $(.048)$ \\
\hline Quebec $^{f}$ & $-.120 * * *$ & $(.031)$ & $-.153 * * *$ & $(.043)$ & $-.152 * * *$ & $(.043)$ \\
\hline Alberta $^{f}$ & .032 & $(.043)$ & .072 & $(.048)$ & .066 & $(.047)$ \\
\hline Prairies ${ }^{f}$ & -.022 & $(.046)$ & .020 & $(.052)$ & .012 & $(.050)$ \\
\hline British Columbia $^{f}$ & .072 & $(.039)$ & .123 & $(.058)$ & $.125^{*}$ & $(.058)$ \\
\hline Large population ${ }^{g-}$ & $.083^{*}$ & $(.040)$ & .070 & $(.049)$ & .071 & $(.048)$ \\
\hline Medium population $^{g}$ & .061 & $(.040)$ & .049 & $(.049)$ & .050 & $(.053)$ \\
\hline Small population $^{g}$ & .012 & $(.045)$ & .026 & $(.063)$ & .024 & $(.063)$ \\
\hline Fixed intercept & $2.826 * * *$ & $(.039)$ & $2.930 * * *$ & $(.166)$ & $2.946^{* * *}$ & $(.165)$ \\
\hline \multicolumn{7}{|l|}{ Random Effects } \\
\hline Mastery intercept $\left(\tau_{00}\right)$ & $.009 * *$ & $(.003)$ & $.009 * *$ & $(.003)$ & $.009 * *$ & $(.003)$ \\
\hline Insecurity intercept $\left(\tau_{11}\right)$ & $.022 *$ & $(.012)$ & $.022 *$ & $(.012)$ & .017 & $(.012)$ \\
\hline
\end{tabular}

${ }^{\dagger}<.10, * \mathrm{p}<.05,{ }^{* *} \mathrm{p}<.01, * * * \mathrm{p}<.001$ (two-tailed test).

Notes: Unstandardized OLS coefficients reported from multilevel analyses. Standard errors presented in parentheses. ${ }^{a}$ Compared to all other levels of education. ${ }^{b}$ Compared to cohabiting, single, and previously married. ${ }^{c}$ Compared to private or government workers. ${ }^{d}$ Compared to $\$ 25,001$ to $\$ 50,000 .{ }^{e}$ Compared to Executives.

${ }^{f}$ Compared to Ontario. ${ }^{g}$ Compared to a metro population. 
Table 4 Psychological Distress Regressed on Perceived Job Insecurity, Unemployment Rates, and Selected Covariates $(N=3,900)$

\begin{tabular}{|c|c|c|c|c|c|c|c|c|}
\hline \multirow{2}{*}{ Focal Variables } & \multicolumn{2}{|c|}{ Model 1} & \multicolumn{2}{|c|}{ Model 2} & \multicolumn{2}{|c|}{ Model 3} & \multicolumn{2}{|c|}{ Model 4} \\
\hline & & & & & & & & \\
\hline Job insecurity & \multicolumn{2}{|c|}{$.224 * * *(.036)$} & \multicolumn{2}{|c|}{$.230 * * *(.036)$} & \multicolumn{2}{|c|}{$.437 * * *(.101)$} & $.243 *$ & $(.101$ \\
\hline Unemployment rate (cen. div.) & \multicolumn{2}{|c|}{ - } & -.013 & $.008)$ & -.010 & $(.009)$ & $-.005^{*}$ & $(.00 \varepsilon$ \\
\hline $\begin{array}{l}\text { Median } \$ \text { of dwelling }(\$ 100,000) \text { (cen. } \\
\text { div). }\end{array}$ & \multicolumn{2}{|c|}{ - } & .023 & $.020)$ & .048 & $(.031)$ & .014 & $(.02($ \\
\hline \% HS dropouts, 25 to 64 (cen. div). & \multicolumn{2}{|c|}{ - } & -.002 & $.004)$ & -.002 & $(.004)$ & -.003 & $(.00<$ \\
\hline$\%$ Christians (cen. div). & \multicolumn{2}{|c|}{ - } & $-.006^{*} \quad($. & $.003)$ & $-.005^{*}$ & $(.003)$ & -.003 & $(.00$ \\
\hline \multicolumn{9}{|l|}{ Interaction Term } \\
\hline Job insecurity $\mathrm{x}$ unemp. rate & \multicolumn{2}{|c|}{ - } & \multicolumn{2}{|l|}{ - } & $-.026^{*}$ & $(.012)$ & -.015 & $(.01$ \\
\hline \multicolumn{9}{|l|}{ Psychological Resources } \\
\hline Mastery & \multicolumn{2}{|c|}{ - } & \multicolumn{2}{|c|}{ - } & \multicolumn{2}{|l|}{ - } & \multicolumn{2}{|c|}{$-.684 * * *(.01$} \\
\hline \multicolumn{9}{|l|}{ Control Measures } \\
\hline Women & $.137 * *$ & $*(.025)$ & $.138 * * *$ & $(.025)$ & $.137 * * *$ & $(.025)$ & $.154 * *$ & $*(.02$ \\
\hline Age & $-.002 *$ & $(.001)$ & $-.002 *$ & $(.001)$ & $-.002 *$ & $(.001)$ & \multicolumn{2}{|c|}{$-.005^{* * *}(.00$} \\
\hline Age squared & $-.001 * *$ & $*(.001)$ & $-.001 * * *$ & $(.001)$ & $-.001 * * *$ & $(.001)$ & \multicolumn{2}{|c|}{$-.001 * * *(.00$} \\
\hline College educated $^{a}$ & -.027 & $(.026)$ & -.027 & $(.026)$ & -.029 & $(.027)$ & -.025 & $(.02$ \\
\hline Married $^{b}$ & $-.092 * *$ & $*(.027)$ & $-.091 * * *$ & $(.027)$ & $-.091 * * *$ & $(.027)$ & $-.050 *$ & $(.02$ \\
\hline Number of children & .004 & $(.013)$ & .005 & $(.013)$ & .006 & $(.013)$ & -.004 & $(.01$ \\
\hline For-profit business ${ }^{c}$ & $-.048 * *$ & $(.026)$ & $-.048 * *$ & $(.026)$ & $-.050 * *$ & $(.026)$ & $-.065 * *$ & $(.02$ \\
\hline$\$ 25,000$ or less ${ }^{d}$ & $.142 * *$ & $*(.035)$ & $.147 * * *$ & $(.035)$ & $.152 * * *$ & $(.035)$ & $.103^{* *}$ & $*(.03$ \\
\hline$\$ 50,001$ to $\$ 75,000^{d}$ & -.061 & $(.033)$ & -.061 & $(.033)$ & -.061 & $(.035)$ & -.015 & $(.02$ \\
\hline$\$ 75,001$ to $\$ 100,000^{d}$ & -.044 & $(.040)$ & -.044 & $(.040)$ & -.047 & $(.040)$ & .056 & $(.03$ \\
\hline$\$ 100,001$ to $\$ 125,000^{d}$ & -.117 & $(.066)$ & -.120 & $(.066)$ & -.120 & $(.066)$ & -.007 & $(.05$ \\
\hline More than $\$ 125,000^{d}$ & -.114 & $(.065)$ & -.112 & $(.065)$ & -.111 & $(.065)$ & -.036 & $(.05$ \\
\hline Work hours & .001 & $(.001)$ & .001 & $(.001)$ & .001 & $(.001)$ & .001 & $(.00$ \\
\hline Professional $^{e}$ & -.047 & $(.045)$ & -.045 & $(.045)$ & -.046 & $(.045)$ & -.089 & $(.03$ \\
\hline Service $^{e}$ & -.053 & $(.051)$ & -.052 & $(.051)$ & -.056 & $(.051)$ & -.099 & $(.04$ \\
\hline Sales $^{e}$ & -.066 & $(.058)$ & -.060 & $(.058)$ & -.057 & $(.058)$ & $-.135 * *$ & $(.05$ \\
\hline Administrative $^{e}$ & -.018 & $(.056)$ & -.016 & $(.056)$ & -.017 & $(.056)$ & -.091 & $(.04$ \\
\hline Production $^{e}$ & $-.114^{*}$ & $(.050)$ & $-.110^{*}$ & $(.051)$ & $-.110^{*}$ & $(.051)$ & $-.179 *$ & $(.04$ \\
\hline Technical $^{e}$ & $-.123 *$ & $(.049)$ & $-.120 *$ & $(.050)$ & $-.118^{*}$ & $(.050)$ & $-.126^{*}$ & $(.04$ \\
\hline White & -.052 & $(.032)$ & -.054 & $(.032)$ & -.054 & $(.032)$ & -.002 & $(.02$ \\
\hline Atlantic ${ }^{f}$ & $-.141^{*}$ & $(.055)$ & $-.048 * *$ & $(.062)$ & $-.052^{*}$ & $(.032)$ & $-.062 *$ & $(.05$ \\
\hline Quebec $^{f}$ & $.081 *$ & $(.040)$ & $-.146^{* *}$ & $(.055)$ & $.145^{* *}$ & $(.055)$ & $.042 * *$ & $(.04$ \\
\hline Alberta $^{f}$ & .016 & $(.055)$ & -.041 & $(.061)$ & -.034 & $(.060)$ & .011 & $(.05$ \\
\hline Prairies ${ }^{f}$ & -.034 & $(.060)$ & -.084 & $(.067)$ & -.075 & $(.067)$ & -.060 & $(.06$ \\
\hline British Columbia $^{f}$ & -.200 & $(.049)$ & -.135 & $(.075)$ & -.131 & $(.074)$ & -.060 & $(.06$ \\
\hline Large population ${ }^{g-}$ & .001 & $(.049)$ & .061 & $(.061)$ & .063 & $(.061)$ & .101 & $(.05$ \\
\hline Medium population ${ }^{g}$ & -.083 & $(.045)$ & .006 & $(.068)$ & .007 & $(.061)$ & .031 & $(.06$ \\
\hline Small population ${ }^{g}$ & -.182 & $(.051)$ & -.039 & $(.081)$ & -.035 & $(.081)$ & -.015 & $(.07$ \\
\hline Fixed intercept & $2.218 * * *$ & $(.071)$ & $2.737 * * *$ & $(.023)$ & $2.689 * * *$ & $(.234)$ & $2.456^{* *}$ & $*(.21$ \\
\hline Random Effects & & & & & & & & \\
\hline Distress intercept $\left(\tau_{00}\right)$ & $.007 *$ & $(.003)$ & $.007 *$ & $(.003)$ & $.007 *$ & $(.003)$ & $.006^{*}$ & $(.00$ \\
\hline Insecurity intercept $\left(\tau_{11}\right)$ & $.045^{*}$ & $(.021)$ & $.041 *$ & $(.020)$ & $.034 *$ & $(.019)$ & $.058 * *$ & $(.02$ \\
\hline
\end{tabular}

$\mathrm{p}<.10,{ }^{*} \mathrm{p}<.05, * * \mathrm{p}<.01, * * * \mathrm{p}<.001$ (two-tailed test).

Notes: Unstandardized OLS coefficients reported from multilevel analyses. Standard errors presented in

parentheses. ${ }^{a}$ Compared to all other levels of education. ${ }^{b}$ Compared to cohabiting, single, and previously married. ${ }^{c}$

Compared to private or government workers. ${ }^{d}$ Compared to $\$ 25,001$ to $\$ 50,000 .{ }^{e}$ Compared to Executives. ${ }^{f}$

Compared to Ontario. ${ }^{g}$ Compared to a metro population. 
Figure 1 The Association between Job Insecurity and Mastery by Unemployment Rates $(N=3,900)$

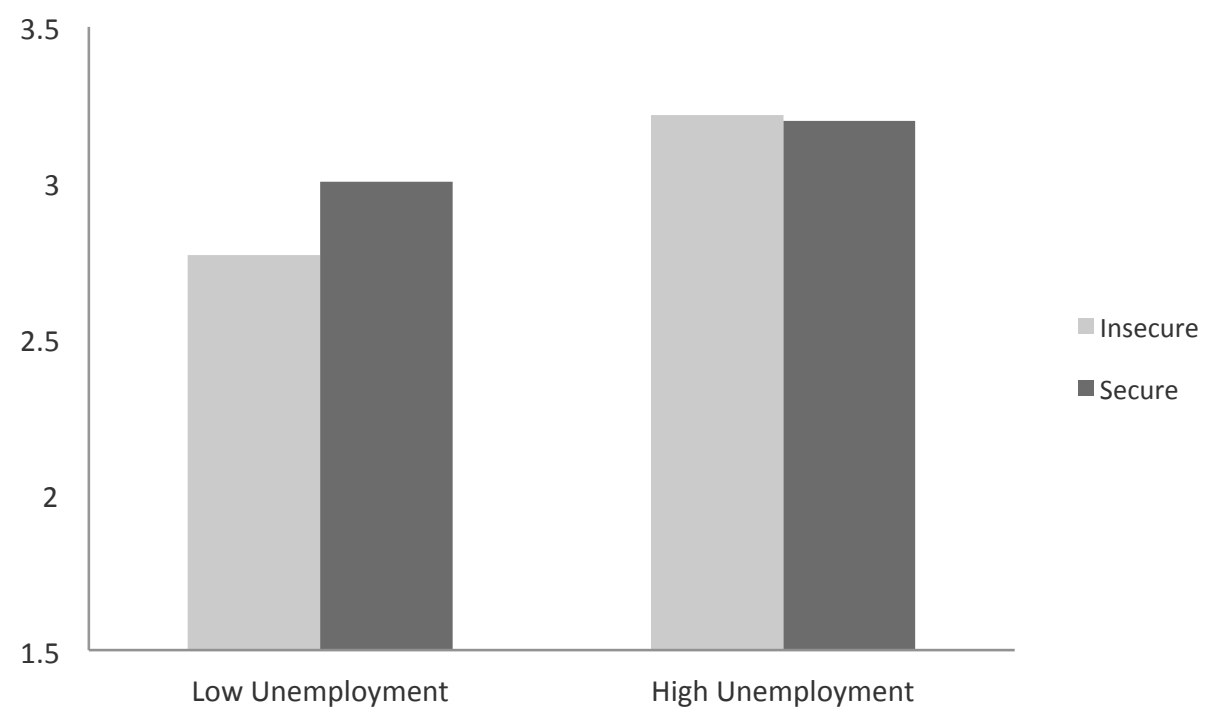

Note: Predicted values of mastery are based on results shown in model 3 of Table 3 . All continuous values are held constant at their respective means. Low and high unemployment reflect the $10^{\text {th }}$ and $90^{\text {th }}$ percentile, respectively. Solving for other values will alter the intercept but not the slope representing the association between job insecurity and mastery by unemployment levels. 
Figure 2 The Association between Job Insecurity and Distress by Unemployment Rates $(N=3,900)$

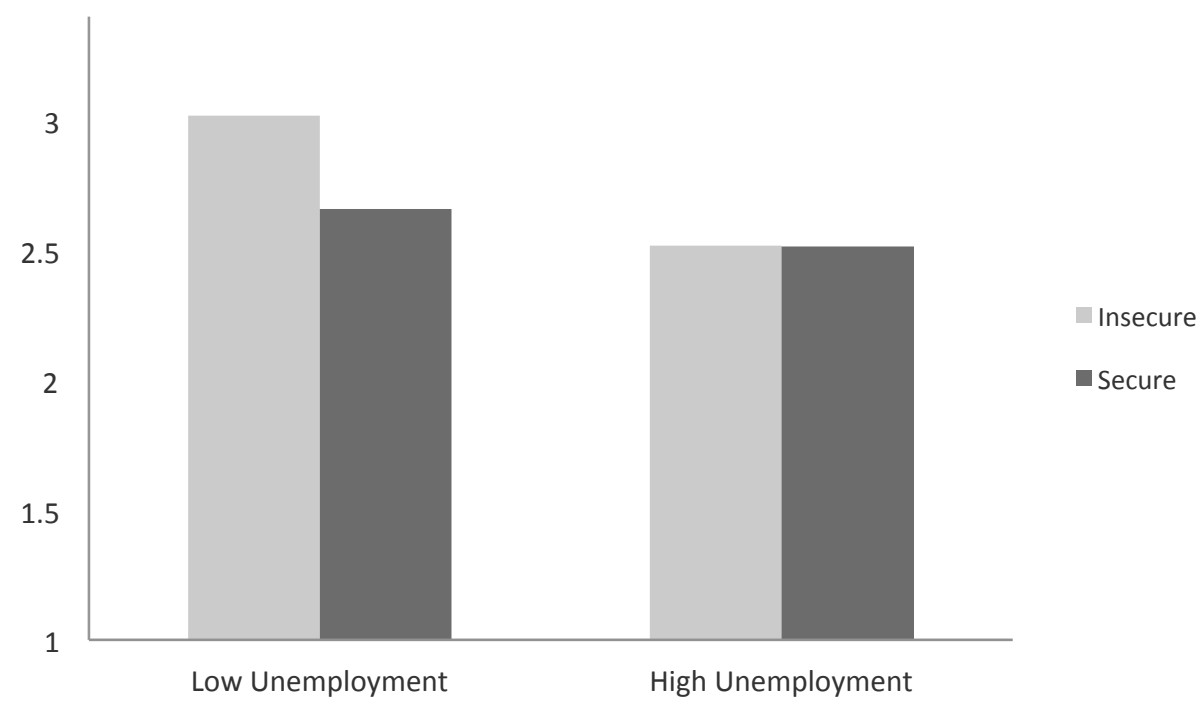

Note: Predicted values of distress are based on results shown in model 3 of Table 4 . All continuous values are held constant at their respective means. Low and high unemployment reflect the $10^{\text {th }}$ and $90^{\text {th }}$ percentile, respectively. Solving for other values will alter the intercept but not the slope representing the association between job insecurity and distress by unemployment levels. 
Figure 3 The Association between Job Insecurity and Distress by Unemployment Rates Controlling for Mastery Levels $(N=3,900)$

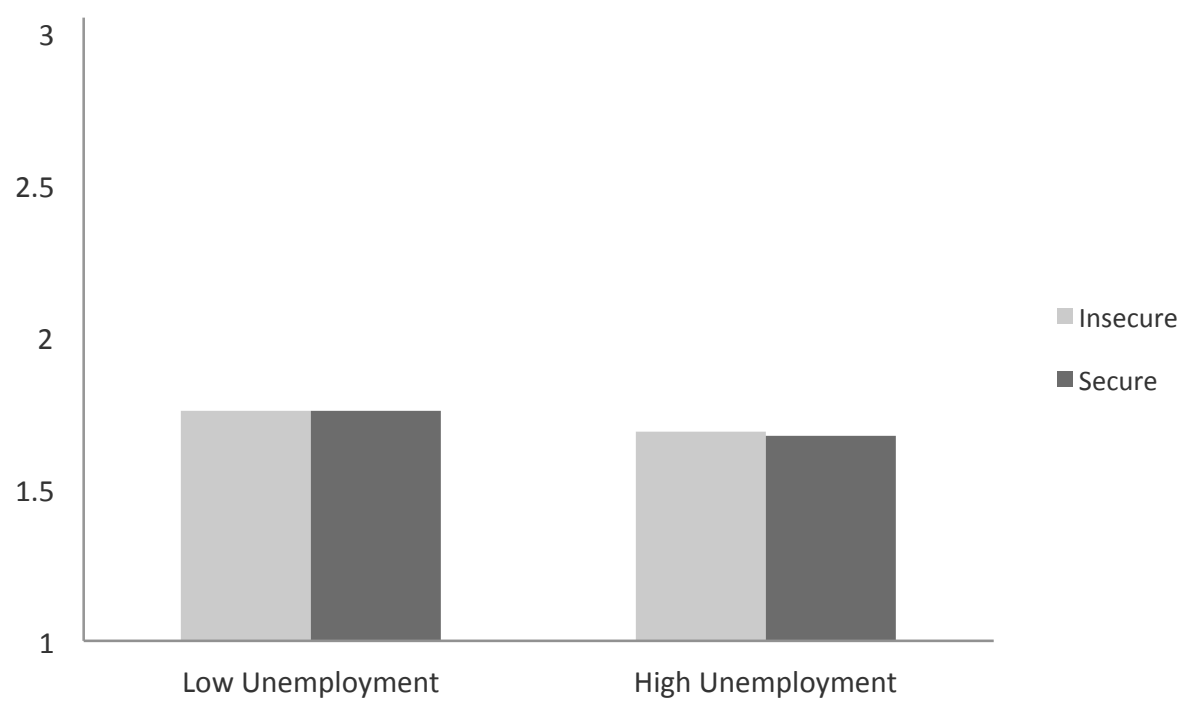

Note: Predicted values of distress are based on results shown in model 4 of Table 4 . All continuous values are held constant at their respective means. Low and high unemployment reflect the $10^{\text {th }}$ and $90^{\text {th }}$ percentile, respectively. Solving for other values will alter the intercept but not the slope representing the association between job insecurity and distress by unemployment levels controlling for mastery levels. 
Appendix A. Empirical Bayes Job Insecurity Slopes for Mastery and Distress Excluding Control Variables by Selected Divisions

\begin{tabular}{ccc}
\hline & Mastery & Distress \\
\hline $\begin{array}{c}\text { Division Location } \\
\text { and Number }\end{array}$ & EB Slope & EB Slope \\
& & \\
\hline 1001 & .138 & -.157 \\
1006 & -.001 & .001 \\
1010 & -.004 & .021 \\
1218 & .000 & -.033 \\
1309 & .145 & -.246 \\
2416 & -.009 & .041 \\
2439 & -.125 & .118 \\
2461 & .005 & -.066 \\
3510 & .069 & -.109 \\
3529 & -.142 & .044 \\
4611 & -.018 & -.056 \\
\hline
\end{tabular}




\section{Author Biographies}

Paul Glavin is an Assistant Professor of sociology at McMaster University. His research examines the social determinants of worker well-being and how employment experiences involving control and uncertainty contribute to social inequalities in mental health.

Marisa Young is an Assistant Professor in the Department of Sociology at McMaster University. Her previous research has examined gender differences in experiences and mental health consequences of work and family stressors. She is currently working on a series of projects in Canada and the U.S. examining the combined impact of work, family, and neighborhood contexts on individuals' perceptions of stressors and their mental health consequences. 